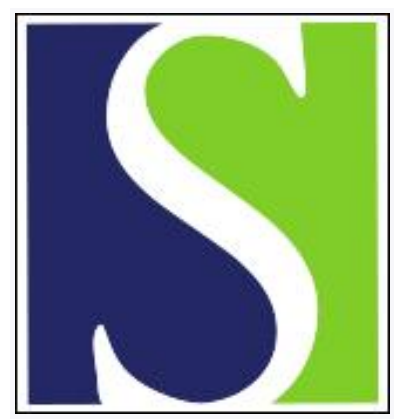

Scand J Work Environ Health 2018;44(3):265-273

https://doi.org/10.5271/sjweh.3709

Published online: 22 Jan 2018, Issue date: 01 May 2018

Objectively measured physical activity of hospital shift workers

by Loef B, van der Beek AJ, Holtermann A, Hulsegge G, van Baarle D, Proper KI

In this study among healthcare workers, objectively measured leisure-time physical activity levels of shift workers were similar to those of non-shift workers. However, shift workers were less sedentary and more physically active (ie, standing/walking) at work than non-shift workers. Future research should study the health effects of these differences in occupational physical activity between shift and non-shift workers.

Affiliation: Center for Nutrition, Prevention and Health Services, National Institute for Public Health and the Environment, P.O. Box 1, 3720 BA, Bilthoven, The Netherlands. karin.proper@rivm.nl

Refers to the following texts of the Journal: 2010;36(2):96-108 2017;43(2):127-135

The following articles refer to this text: 2020;46(3):293-301; 2020;46(5):516-524

Key terms: accelerometry; healthcare worker; hospital; hospital worker; leisure-time physical activity; night shift work; night work; objective measure; occupational health; occupational health; occupational physical activity; physical activity; shift work; shift worker; workhour

This article in PubMed: www.ncbi.nlm.nih.gov/pubmed/29355291

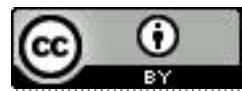




\title{
Objectively measured physical activity of hospital shift workers
}

\author{
by Bette Loef, MSc, ${ }^{1,2}$ Allard J van der Beek, PhD, ${ }^{2}$ Andreas Holtermann, PhD, ${ }^{3}$ Gerben Hulsegge, PhD, 1, 2 Debbie van Baarle,
} PhD, ${ }^{4}$ Karin I Proper, PhD ${ }^{1}$

Loef B, van der Beek A, Holtermann A, Hulsegge G, van Baarle D, Proper Kl. Objectively measured physical activity of hospital shift workers. Scand J Work Environ Health. 2018;44(3):265-273. doi:10.5271/sjweh.3709

Objectives Shift work may alter workers' leisure-time and occupational physical activity (PA) levels, which might be one of the potential underlying mechanisms of the negative health effects of shift work. Therefore, we compared objectively measured PA levels between hospital shift and non-shift workers.

Methods Data were used from Klokwerk+, a cohort study examining the health effects of shift work among healthcare workers employed in hospitals. In total, 401 shift workers and 78 non-shift workers were included, all of whom wore Actigraph GT3X accelerometers for up to seven days. Time spent sedentary, standing, walking, running, stairclimbing, and cycling during leisure time and at work was estimated using Acti4 software. Linear regression was used to compare proportions of time spent in these activities between hospital shift and non-shift workers.

Results Average accelerometer wear-time was 105.9 [standard deviation (SD) 14.0] waking hours over an average of 6.9 (SD 0.6) days. No differences between hospital shift and non-shift workers were found in leisure-time $\mathrm{PA}(\mathrm{P}>0.05)$. At work, shift workers were less sedentary $[\mathrm{B}=-10.6 \%(95 \% \mathrm{CI}-14.3--6.8)]$ and spent larger proportions of time standing $[\mathrm{B}=9.5 \%(95 \% \mathrm{CI} 6.4-12.6)]$ and walking $[\mathrm{B}=1.2 \%(95 \% \mathrm{CI} 0.1-2.2)]$ than non-shift workers. However, these differences in occupational PA became smaller when the number of night shifts during accelerometer wear-time increased.

Conclusions Leisure-time PA levels of hospital shift workers were similar to those of non-shift workers, but shift workers were less sedentary and more physically active (ie, standing/walking) at work. Future research to the role of occupational activities in the health effects of shift work is recommended.

Key terms accelerometry; healthcare worker; hospital worker; leisure-time physical activity; night shift work; night work; objective measure; occupational health; occupational physical activity; shift work; workhour.

In the healthcare sector, patients need care 24/7. This requires employees to work in shifts around the clock. Due to the increasing societal need for continuous service, (night) shift work is also widespread among other sectors. Approximately $19 \%$ of European workers report to work during the night (1). For the worker, shift work may have adverse health consequences. Working in shift schedules, and especially those including night shifts, has been linked to an increased risk for the development of diseases and metabolic disturbances, such as cancer, cardiovascular diseases, and body weight gain (2-5).
Multiple pathways have been proposed to connect shift work to its possible negative health effects, with unhealthy lifestyle behaviors being one of them (6-9). To date, several studies have investigated the PA levels of shift workers. Some studies found shift workers to be less physically active compared to non-shift workers (10-12), supporting the hypothesis that shift workers may have less time and energy to engage in PA in their leisure time (13). In addition, another explanation for differences in PA between hospital shift and non-shift workers might be differences in physical workload

1 Center for Nutrition, Prevention and Health Services, National Institute for Public Health and the Environment, Bilthoven, The Netherlands.

2 Department of Public and Occupational Health, Amsterdam Public Health research institute, VU University Medical Center Amsterdam, The Netherlands.

3 National Research Centre for the Working Environment, Copenhagen, Denmark.

4 Center for Immunology of Infectious Diseases and Vaccins, National Institute for Public Health and the Environment, Bilthoven, The Netherlands.

Correspondence to: Karin I. Proper, PhD, Center for Nutrition, Prevention and Health Services, National Institute for Public Health and the Environment, P.O. Box 1, 3720 BA, Bilthoven, The Netherlands. [E-mail: karin.proper@rivm.nl] 
due to varying work tasks, patients, and availability of resources and staff during different types of shifts (14). However, most studies did not find a clear association between shift work and PA (15-21).

An explanation for the inconclusive evidence as to the PA of shift workers may be the use of self-reported measures of PA $(10-12,15,16,18,20-22)$, which are highly susceptible to bias $(23,24)$. Although objective measures of PA are increasingly being used in epidemiological research, there is a scarcity of studies that used such instruments to determine PA levels of shift workers. A second explanation for the mixed findings on the PA levels in shift workers may be related to the use of overall PA measures, which do not distinguish between different types of PA. As different types of PA (eg, sitting/ walking/running) may have independent effects on health (25-27), the previously often-used overall measures of PA are insufficient to establish an adequate overview of shift workers' PA level. In this context, it is also important to differentiate between leisure-time and occupational PA because their health effects may be different or even opposite (28-31). Lastly, studies with limited information on shift work status may not provide a clear insight into PA levels of shift workers. Therefore, the aim of the present study was to compare objectively measured leisure-time and occupational PA levels of different physical activities between hospital shift and non-shift workers. In addition, to our knowledge, no studies have examined leisure-time and occupational PA levels during specific shift schedules. Hence, it is possible that most studies did not find an association between shift work and PA because they studied the average PA level of shift workers without looking into differences during, for example, periods with and without night shifts. Therefore, the second aim of our study was to examine the association between shift work and leisure-time and occupational PA for work schedules with different number of night shifts.

\section{Methods}

\section{Study population and design}

In this cross-sectional study, baseline data were used from the Klokwerk+ study. Klokwerk+ is a prospective cohort study among men and women aged 18-65 years that aims to investigate the effects of (night-) shift work on body weight and infection susceptibility and the mechanisms underlying these effects (32). Details of the study protocol of Klokwerk+ have been described elsewhere (32). In total, 611 healthcare workers from six hospitals in the Netherlands participated in the baseline measurement of Klokwerk+ (figure 1), consisting of anthropometric measurements, a questionnaire, a food diary, and accel- erometry. In the current study, 401 shift workers and 78 non-shift workers who wore an accelerometer on their right thigh to measure PA were included (figure 1).

\section{Measures}

Shift work. To adequately determine shift work exposure in Klokwerk+, questions related to shift work were based on the international consensus report by Stevens et al $(32,33)$. Participants were asked whether they ever worked or currently work night shifts (24:00-06.00 hours) and rotating shifts (rotating between day, night, evening, and/or sleep shifts). For both night and rotating shifts, they reported the start and (if applicable) stop date and the total number of years working in these particular shifts. Subsequently, participants were categorized into two groups: non-shift workers (ie, working neither rotat-

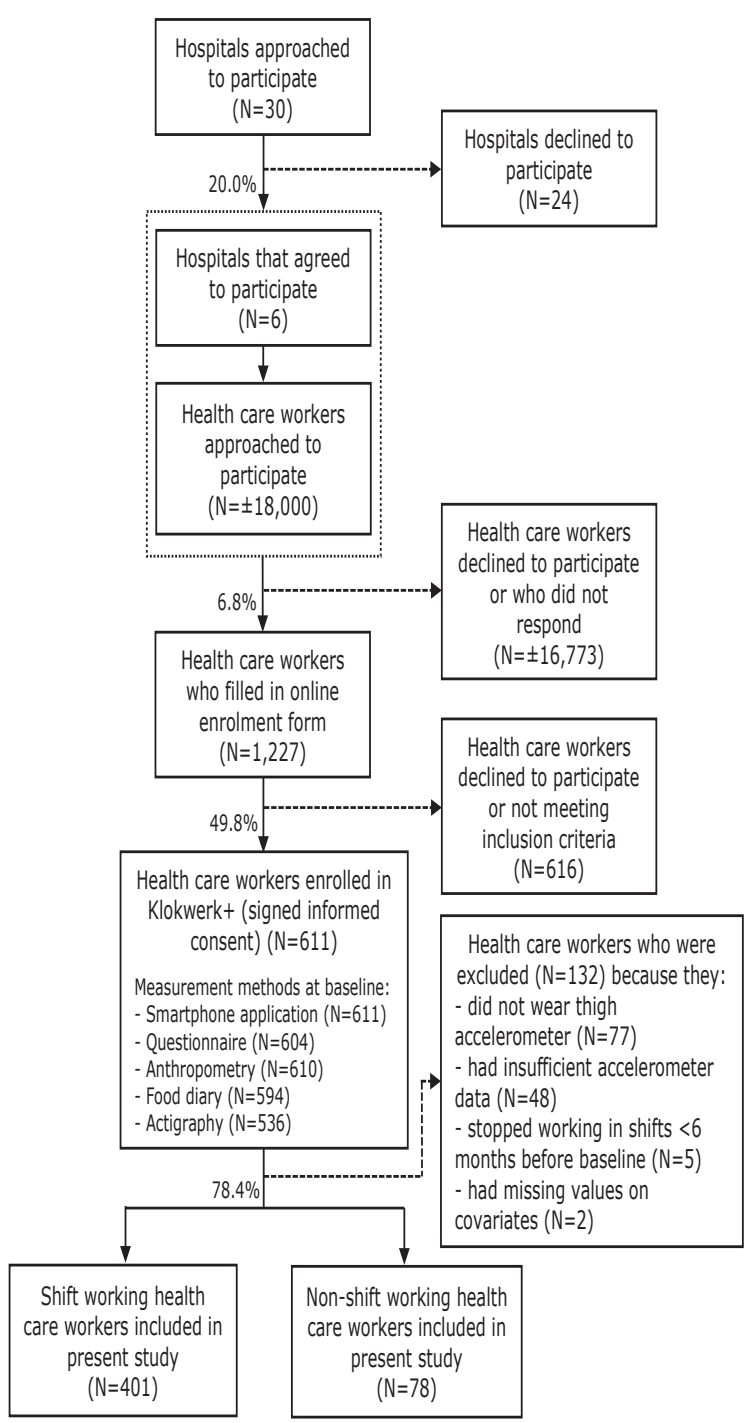

Figure 1. Flowchart of study participants. 
ing nor night shifts for $\geq 6$ months) and shift workers (ie, working rotating and/or night shifts).

Furthermore, the shifts reported in the diaries that participants kept during accelerometer wear-time were categorized into day shifts (mostly between $07.30-16.00$ hours), evening shifts (mostly between 15.00-23.00 hours), and night shifts (mostly between 23.00-07.45 hours). The number of night shifts during accelerometer wear-time for each participant was counted and categorized into: $0,1-2$, and $\geq 3$ night shifts during accelerometer wear-time.

Physical activity. PA was measured objectively using triaxial accelerometers (Actigraph GT3X devices, Actigraph, Pensacola, FL, USA) taped to the medial front of the right thigh, halfway between knee and hip $(34,35)$. Participants were instructed to wear the accelerometers continuously over seven consecutive days. During this time, they kept a diary in which they reported their working and sleep hours as well as non-wear-time. At the start of the measurement, the researchers asked the participant to stand in an upright position for approximately 15 seconds in order to obtain a reference measurement. Data from the accelerometers were downloaded using the Actilife software (version 5.5) from the manufacturer. Further analysis of the data was done using the Acti4 software (NRCWE, Copenhagen, Denmark and BAuA, Berlin, Germany). By using validated algorithms and the individual's reference measurement, the Acti4 software is able to discriminate between different PA types and estimate the time spent in these activities with high sensitivity and specificity (35). Subsequently, estimates were obtained on time spent in the following physical activities and body postures: sedentary (sitting/lying), standing, walking, running, stairclimbing, and cycling.

Sleep hours, non-wear-time, and periods not covered in the diary were excluded from the data analysis. To exclude periods of wear-time that may be unrepresentative for the participant $(17,34,36)$, the leisure- and working-time periods for working days had to consist of $\geq 4$ hours/day of wear-time and/or $75 \%$ of the average wear-time across working days. For non-working days, the leisure-time periods had to consist of $\geq 10$ hours/ day of wear-time and/or $75 \%$ of the average wear-time across days (17). Furthermore, based on the criterion of $\geq 4$ valid wearing days of 10 hours/day that is often used in previous work $(24,37,38)$, only participants with $\geq 40$ hours of wear-time including $\geq 4$ working hours and $\geq 10$ hours of leisure time were included.

Based on the working hours reported in the diaries, a distinction was made between PA during leisure (including commuting and household activities) and PA at work. Time spent in each type of PA was calculated and expressed as the percentage of total time, separately for leisure and work.

\section{Covariates}

Included covariates were age, gender, marital status (married/living together versus not married/living together), educational level (low: intermediate vocational education/higher secondary education versus high: higher vocational education/university), smoking (current smoker/non-smoker), chronotype (morning type/evening type/intermediate type), and occupation (nurse/other occupation). All occupations involved contact with patients. Almost three quarters of participants were nurses, but other occupations included mostly physicians and other medical professionals such as dieticians, physiotherapists, and occupational therapists.

\section{Statistical analysis}

Baseline characteristics of hospital non-shift and shift workers were compared using the independent samples t-test and Chi-square test. To gain more insight into differences in occupational PA between shift and non-shift workers within one occupational group, proportions of working time spent in different PA types were reported for the total study population and the subsample of nurses. Linear regression analysis was used to compare proportions of total leisure and working time spent in different types of PA between shift and non-shift workers. Analyses were adjusted for age, gender, marital status, educational level, smoking, and occupation. Possible effect modification of chronotype was examined. As the P-values of the interaction terms between shift work and chronotype were $>0.05$, results were not stratified for chronotype. Furthermore, leisure-time and occupational PA levels of shift workers with $0,1-2$, or $\geq 3$ night shifts during accelerometer wear-time were compared to those of non-shift workers using linear regression analysis. Analyses were carried out using IBM SPSS Statistics, V.24.0 (IBM Corp, Armonk, NY, USA).

\section{Results}

Average wear-time of the accelerometers during waking hours was 105.9 [standard deviation (SD) 14.0] hours over an average of 6.9 (SD 0.6) wearing days. No differences in average wear-time were found between hospital non-shift and shift workers (table 1). Table 1 shows that most participants were female (87.1\%). Furthermore, shift workers were younger [40.9 (SD 12.2) years] than non-shift workers [47.3 (SD 10.8) years], and they were less often highly educated (55.9\%) than non-shift workers $(71.8 \%)$. With respect to occupation, $80.5 \%$ of shift workers were nurses compared to $33.3 \%$ of non-shift workers. Furthermore, compared to non-shift workers, 
shift workers were less often medical professionals other than nurses $(5.5 \%$ versus $15.4 \%)(\mathrm{P}<0.05)$.

Table 2 shows that the proportions of time spent in any of the leisure-time PA types did not differ between hospital non-shift and shift workers. In contrast, the percentages of shift workers' working time spent standing (37.7\%) and walking (11.8\%) were significantly higher than the standing $(26.0 \%)$ and walking $(9.9 \%)$ percentages at work for non-shift workers $(\mathrm{P}<0.05)$. Furthermore, shift workers spent half of the time sedentary at work, while non-shift workers spent $63.5 \%$ of working time sedentary $(\mathrm{P}<0.05)$. With respect to stairclimbing at work, shift workers spent less time stairclimbing $(0.25 \%)$ than non-shift workers $(0.40 \%)$. Similar differences in occupational PA were found between shift and non-shift workers in the subsample of nurses.

A similar pattern for the differences in PA types appeared in the results of the multivariable-adjusted analyses (table 3). There were no significant differences between hospital shift and non-shift workers in the PA types during leisure time. At work, shift workers were $10.6 \%(95 \%$ CI $-14.3--6.8)$ less sedentary and spent a larger proportion of time standing $[\mathrm{B}=9.5 \%(95 \% \mathrm{CI}$ 6.4-12.6)] and walking [B=1.2\% (95\% CI 0.1-2.2)] than non-shift workers. Furthermore, shift workers spent less time in stairclimbing at work than non-shift workers $[\mathrm{B}=-0.14(95 \% \mathrm{CI}-0.20--0.07)]$.

Regression coefficients of PA types for hospital shift workers who worked $0,1-2$, or $\geq 3$ night shifts/ week during accelerometer wear-time compared to non-shift workers are presented in table 4 . The regression coefficients for leisure time showed that, compared

Table 1. Characteristics of the study population stratified for hospital non-shift workers and shift workers. [SD=standard deviation.]

\begin{tabular}{|c|c|c|c|c|c|c|}
\hline & \multicolumn{3}{|c|}{ Non-shift workers $(\mathrm{N}=78)$} & \multicolumn{3}{|c|}{$\begin{array}{l}\text { Shift workers } \\
\quad(N=401)\end{array}$} \\
\hline & $\%$ & Mean & SD & $\%$ & Mean & SD \\
\hline Age (in years) & & $47.3^{a}$ & 10.8 & & $40.9^{a}$ & 12.2 \\
\hline Gender (female) & 83.3 & & & 87.8 & & \\
\hline Educational level (high) & $71.8^{a}$ & & & 55.9 a & & \\
\hline $\begin{array}{l}\text { Marital status (married/liv- } \\
\text { ing together) }\end{array}$ & 80.8 & & & 72.3 & & \\
\hline Smoker (yes) & $3.8^{a}$ & & & $12.2^{\mathrm{a}}$ & & \\
\hline Occupation (nurse) & $33.3^{a}$ & & & $80.5^{a}$ & & \\
\hline $\begin{array}{l}\text { Worked night shift(s) } \\
\text { during measurement (yes) }\end{array}$ & & & & 37.2 & & \\
\hline \multicolumn{7}{|c|}{ Average accelerometer wear- time } \\
\hline In total hours & & 105.2 & 12.7 & & 106.0 & 14.3 \\
\hline During leisure time & & 75.2 & 12.1 & & 75.3 & 14.4 \\
\hline At work & & 30.0 & 9.1 & & 30.7 & 11.8 \\
\hline In total days & & 6.9 & 0.6 & & 6.9 & 0.6 \\
\hline Non-working days & & 3.2 & 1.0 & & 3.2 & 1.3 \\
\hline Working days & & 3.6 & 1.1 & & 3.6 & 1.3 \\
\hline
\end{tabular}

a Statistically significant difference $(P<0.05)$ between shift workers and nonshift workers tested with independent-samples t-test and chi-square test. to those of non-shift workers, leisure-time PA types of shift workers with different number of night shifts per week were similar. However, for working time, with an increase in the number of night shifts, the differences in proportions of time spent sedentary, standing, and walking between shift and non-shift workers became smaller. For example, compared to non-shift workers, shift workers who did not work night shifts during accelerometer wear-time spent $11.7 \%$ (95\% CI -15.5- -7.9) less time sedentary at work, while this difference was $7.5 \%(95 \%$ CI -12.6- -2.4) for shift workers who worked $\geq 3$ night shifts. Furthermore, shift workers who did not work night shifts during accelerometer wear-time walked $1.4 \%(95 \%$ CI $0.3-2.5)$ more at work than non-shift workers, but this difference was smaller and statistically non-significant for shift workers who worked 1-2 night shifts $[\mathrm{B}=0.8 \%(95 \% \mathrm{CI}-0.5-2.1)]$ and $\geq 3$ night shifts $[\mathrm{B}=0.5 \%(95 \% \mathrm{CI}-1.0-1.9)]$.

\section{Discussion}

In this study among healthcare workers, objectively measured leisure-time PA levels of hospital shift workers were similar to those of non-shift workers. At work, hospital shift workers were less sedentary and spent more time standing and walking than non-shift workers. However, it appeared that these differences between shift and non-shift workers in proportions of time spent sedentary, standing, and walking at work became smaller when the number of night shifts worked during accelerometer wear-time increased. The number of night shifts worked during accelerometer wear-time was not associated with leisure-time PA.

Most previous studies evaluating leisure-time PA levels of shift workers using self-reported PA measures found no differences between shift and non-shift workers $(16,18,21,39,40)$. Although in the current study PA was measured objectively and different PA types were taken into account, still no support was found for such leisure-time PA differences. In addition, our previous study among blue-collar workers that used objective PA measures also reported shift and non-shift workers to have similar leisure-time PA levels (17). Based on previous and current findings, it can thus be suggested that it is in general unlikely that leisure-time PA levels of shift workers differ from those of non-shift workers.

Little research has been done on occupational PA levels of shift workers. Some studies using self-reported measures found no association between shift work and occupational PA $(12,21)$, and other studies found that shift workers reported more occupational PA than nonshift workers $(39,40)$. These previous studies all used one overall measure for total occupational PA, while 
Table 2. The mean and standard deviation of the proportions of leisure time and working time spent in different physical activity types compared between hospital non-shift workers and shift workers, and of working time in the subsample of nurses. [SD=standard deviation]

\begin{tabular}{|c|c|c|c|c|c|c|c|c|c|c|c|c|}
\hline & \multicolumn{4}{|c|}{ Leisure time } & \multicolumn{8}{|c|}{ Working time } \\
\hline & \multicolumn{2}{|c|}{$\begin{array}{c}\text { Non-shift } \\
\text { workers(N=78) }\end{array}$} & \multicolumn{2}{|c|}{$\begin{array}{l}\text { Shift workers } \\
\qquad(\mathrm{N}=401)\end{array}$} & \multicolumn{2}{|c|}{$\begin{array}{l}\text { Non-shift workers } \\
\qquad(\mathrm{N}=78)\end{array}$} & \multicolumn{2}{|c|}{$\begin{array}{l}\text { Shift workers } \\
\qquad(N=401)\end{array}$} & \multicolumn{2}{|c|}{$\begin{array}{l}\text { Non-shift working } \\
\text { nurses }(\mathrm{N}=26)\end{array}$} & \multicolumn{2}{|c|}{$\begin{array}{l}\text { Shift working nurses } \\
\qquad(\mathrm{N}=323)\end{array}$} \\
\hline & Mean $(\%)^{\text {a }}$ & SD & Mean $(\%)^{a}$ & SD & $\operatorname{Mean}(\%)^{a}$ & SD & Mean $(\%)^{a}$ & SD & Mean (\%) a & SD & $\operatorname{Mean}(\%)^{\text {a }}$ & SD \\
\hline Sedentary & 59.5 & 9.2 & 61.4 & 9.7 & $63.5^{b}$ & 16.5 & $50.0^{b}$ & 13.7 & $59.7^{b}$ & 16.0 & $48.6^{b}$ & 12.6 \\
\hline Standing & 27.9 & 6.7 & 26.9 & 7.3 & $26.0^{b}$ & 12.7 & $37.7^{b}$ & 11.6 & $29.3^{b}$ & 13.6 & $38.9^{b}$ & 10.7 \\
\hline Walking & 8.8 & 2.3 & 8.6 & 2.5 & $9.9^{b}$ & 5.5 & $11.8^{b}$ & 3.6 & $10.5^{b}$ & 4.1 & $12.1^{b}$ & 3.4 \\
\hline Running & 0.27 & 0.57 & 0.32 & 0.75 & 0.01 & 0.02 & 0.01 & 0.02 & 0.01 & 0.01 & 0.01 & 0.02 \\
\hline Stair-climbing & 0.76 & 0.42 & 0.77 & 0.54 & $0.40^{b}$ & 0.46 & $0.25^{b}$ & 0.19 & $0.39^{b}$ & 0.30 & $0.24^{b}$ & 0.18 \\
\hline Cycling & 2.66 & 2.90 & 2.03 & 2.72 & 0.25 & 0.57 & 0.18 & 0.74 & 0.13 & 0.29 & 0.18 & 0.79 \\
\hline
\end{tabular}

a $\%$ of total leisure time, and $\%$ of total working time.

${ }^{\mathrm{b}}$ Statistically significant difference $(\mathrm{P}<0.05)$ between shift workers and non-shift workers tested with independent-samples t-test.

Table 3. Regression coefficients of the differences in proportions of leisure time and working time spent in physical activity types between hospital shift workers ( $N=401)$ and non-shift workers $(N=78)$ (reference a). [B=regression coefficient; $C l=$ confidence interval]

\begin{tabular}{|c|c|c|c|c|c|c|c|c|}
\hline & \multicolumn{4}{|c|}{ Leisure time } & \multicolumn{4}{|c|}{ Working time } \\
\hline & \multicolumn{2}{|c|}{ Model $1^{\mathrm{b}}$} & \multicolumn{2}{|c|}{ Model $2^{\circ}$} & \multicolumn{2}{|c|}{ Model $1^{\mathrm{b}}$} & \multicolumn{2}{|c|}{ Model 2 } \\
\hline & $B$ & $95 \% \mathrm{Cl}$ & B & $95 \% \mathrm{Cl}$ & $B$ & $95 \% \mathrm{Cl}$ & B & $95 \% \mathrm{Cl}$ \\
\hline Sedentary & 1.9 & $-0.4-4.3$ & -0.9 & $-3.4-1.6$ & $-13.5^{d}$ & $-17.0--10.1$ & $-10.6^{d}$ & $-14.3--6.8$ \\
\hline Standing & -1.1 & $-2.8-0.7$ & 0.4 & $-1.5-2.3$ & $11.8^{d}$ & 8.9-14.6 & $9.5^{d}$ & 6.4-12.6 \\
\hline Walking & -0.2 & $-0.8-0.4$ & 0.2 & $-0.4-0.9$ & $1.9^{\mathrm{d}}$ & $1.0-2.9$ & $1.2^{\mathrm{d}}$ & $0.1-2.2$ \\
\hline Running & 0.05 & $-0.13-0.22$ & 0.11 & $-0.08-0.31$ & 0.00 & $-0.00-0.01$ & 0.00 & $-0.00-0.01$ \\
\hline Stair-climbing & 0.01 & $-0.12-0.14$ & 0.09 & $-0.05-0.23$ & $-0.16^{d}$ & $-0.22--0.10$ & $-0.14^{d}$ & $-0.20--0.07$ \\
\hline Cycling & -0.63 & $-1.30-0.04$ & 0.16 & $-0.55-0.87$ & -0.07 & $-0.24-0.10$ & -0.00 & $-0.19-0.19$ \\
\hline
\end{tabular}

a Non-shift workers.

${ }^{\mathrm{b}}$ Crude model.

'Adjusted for age, gender, educational level, marital status, smoking status, and occupation.

d $\mathrm{P}<0.05$.

Table 4. Regression coefficients of the differences in proportions of leisure time and working time spent in physical activity types by number of night shifts during accelerometer wear-time ${ }^{\text {a }}$. Reference group= non-shift workers [B=regression coefficient; $\mathrm{Cl}=$ confidence interval].

\begin{tabular}{|c|c|c|c|c|c|c|c|}
\hline & \multicolumn{2}{|c|}{$\begin{array}{c}\text { Shift workers who worked } \\
\text { O night shifts during } \\
\text { accelerometer wear-time }(\mathrm{N}=252)\end{array}$} & \multicolumn{2}{|c|}{$\begin{array}{l}\text { Shift workers who worked } \\
1-2 \text { night shifts during } \\
\text { accelerometer wear-time (N=93) }\end{array}$} & \multicolumn{2}{|c|}{$\begin{array}{l}\text { Shift workers who worked } \\
\geq 3 \text { night shifts during } \\
\text { accelerometer wear-time }(\mathrm{N}=56)\end{array}$} & \multirow[t]{2}{*}{ P-trend ${ }^{b}$} \\
\hline & $B$ & $95 \% \mathrm{Cl}$ & $B$ & $95 \%-\mathrm{Cl}$ & $B$ & $95 \% \mathrm{Cl}$ & \\
\hline \multicolumn{8}{|l|}{ Leisure time } \\
\hline Sedentary & -1.1 & $-3.7-1.5$ & -0.6 & $-3.6-2.4$ & -0.4 & $-3.8-3.0$ & 0.65 \\
\hline Standing & 0.4 & $-1.5-2.4$ & 0.3 & $-2.0-2.6$ & 0.1 & $-2.5-2.7$ & 0.64 \\
\hline Walking & 0.2 & $-0.5-0.9$ & 0.3 & $-0.5-1.1$ & 0.0 & $-0.9-0.9$ & 0.91 \\
\hline Running & 0.11 & $-0.09-0.31$ & 0.11 & $-0.13-0.34$ & 0.10 & $-0.17-0.37$ & 0.96 \\
\hline Stair-climbing & 0.08 & $-0.06-0.23$ & 0.11 & $-0.06-0.28$ & 0.08 & $-0.11-0.27$ & 0.99 \\
\hline Cycling & 0.29 & $-0.44-1.02$ & -0.24 & $-1.10-0.62$ & 0.12 & $-0.86-1.10$ & 0.62 \\
\hline \multicolumn{8}{|l|}{ Working time } \\
\hline Sedentary & $-11.7^{c}$ & $-15.5--7.9$ & $-8.4^{c}$ & $-12.9--3.9$ & $-7.5^{c}$ & $-12.6--2.4$ & 0.01 \\
\hline Standing & $10.4^{c}$ & 7.2-13.6 & $7.8^{\mathrm{c}}$ & $4.1-11.5$ & $7.3^{c}$ & $3.0-11.5$ & 0.03 \\
\hline Walking & $1.4^{\mathrm{c}}$ & $0.3-2.5$ & 0.8 & $-0.5-2.1$ & 0.5 & $-1.0-1.9$ & 0.07 \\
\hline Running & 0.00 & $-0.00-0.01$ & 0.00 & $-0.01-0.01$ & 0.00 & $-0.01-0.01$ & 0.42 \\
\hline Stair-climbing & $-0.11^{c}$ & $-0.18--0.04$ & $-0.20^{c}$ & $-0.28--0.12$ & $-0.21^{c}$ & $-0.30--0.12$ & $<0.01$ \\
\hline Cycling & 0.04 & $-0.16-0.24$ & -0.12 & $-0.35-0.11$ & -0.03 & $-0.29-0.24$ & 0.25 \\
\hline
\end{tabular}

a Adjusted for age, gender, educational level, marital status, smoking status, and occupation.

b P-value for trend was used to calculate trends in the regression coefficients of shift workers with increasing number of night shifts $(0 ; 1$ or 2 ; and $\geq 3$ night shifts) during accelerometer wear-time; for this calculation the non-shift workers were excluded.

c $\mathrm{P}<0.05$. 
in our study different objectively measured activity categories were taken into account. In our study, differences in occupational PA levels between hospital shift and non-shift workers appeared to be rather large. For example, in a 40-hour working week, a difference of $9.5 \%$ in standing comes down to shift workers standing almost 4 hours/week more at work than non-shift workers. This difference in occupational PA cannot be explained by the fact that the night shifts of hospital shift workers involve a lot of standing and walking because we observed that the differences in occupational PA between shift and non-shift workers decreased with an increase in the number of night shifts/week. Therefore, possibly the most likely explanation for the observed difference in occupational PA between hospital shift and non-shift workers is that the tasks that shift workers perform at work require different physical activities than those performed by non-shift workers. The differences in educational level and occupation show that hospital non-shift workers were in general higher educated than shift workers and they were more often medical professionals other than nurses, while most shift workers were nurses (table 1). Educational level and occupation are known to be strongly related to sedentary behavior (41), and therefore results were adjusted for these covariates. Nonetheless, it is still likely that even within occupational groups, the non-shift workers performed more supervisory and management tasks from a fixed workplace while shift workers were more involved in caring tasks across the hospital ward, resulting in differences in occupational PA levels. This is also supported by the finding that the differences in occupational PA between shift and non-shift workers remained within a subsample of workers with the same occupation, ie, nurses (table 2). Future studies on the different tasks of - and PA at work by - shift versus non-shift workers are recommended.

To our knowledge, only two previous studies used accelerometry to examine PA levels of shift workers. Loprinzi (19) found that rotating shift workers were less sedentary and spent more time in light-intensity PA than non-shift workers. As no distinction was made between leisure-time and occupational PA (19), it is possible that these findings can be explained by more light-intensity (standing/walking) PA and less sitting at work, as was found in the present study. Hulsegge et al (17) found that shift workers were more sedentary at work, which is in contrast with the present findings. This inconsistency may partly be explained by the fact that our study was done among healthcare workers with different tasks and job demands during day and night-time compared to the blue-collar workers in the Hulsegge et al study. Hence, this may indicate that differences in occupational PA between shift and non-shift workers may depend on occupational sector and work environment.
Our study adds to the current literature by providing insights into the general PA levels of hospital shift workers as well as into their PA levels during night shift periods. It was expected that leisure-time PA levels would be lower for shift workers who worked one or multiple night shifts during accelerometer wear-time because afterwards they may be too tired to be physically active $(13,42)$. However, our findings did not confirm this hypothesis. Instead, leisure-time PA of hospital shift workers with different numbers of night shifts/week appeared to be similar. This suggests that an increase in the number of night shifts does not result in more sedentary behavior and less PA during leisure time. At work, differences in PA between shift and non-shift workers became less distinct with an increase in the number of night shifts/week. This may indicate that during night shifts, hospital shift workers' job tasks demand less PA than during day shifts. For example, in hospitals, most patients are asleep during the night and only immediate necessary care needs to be provided. To further examine this hypothesis, we compared occupational PA levels during night and day shifts among 82 shift workers who worked both night and day shifts during accelerometer wear-time in a post-hoc analysis. In line with our main results, hospital shift workers appeared to sit more [3.0\% (95\% CI -1.2-7.2)] and stand [-1.9\% (95\% CI -5.3-1.6)] and walk $[-0.9 \%(95 \% \mathrm{CI}-1.8-0.1)]$ less during night compared to day shifts, although these differences were not statistically significant. Possibly, in the healthcare sector, job tasks of shift workers during night shifts differ from those of shift workers during day shifts, but the difference in job tasks between non-shift and shift workers may be even more profound. Further research is needed to confirm this and examine whether this is true for workers in the healthcare sector as well as for those in other occupational sectors.

The observed differences in occupational PA may affect the health of shift workers. Although it is generally believed that excessive sedentary behavior at work should be discouraged due to its association with negative health outcomes (43), prolonged periods of standing at work have also been found to pose health risks for the worker (44). Interrupting these prolonged periods of standing by alternating between sitting and standing may provide recovery and prevent fatigue (44, 45). As particular health risks may exist for prolonged duration of uninterrupted periods of behaviors such as sitting and standing (44), a recommendation for future research would be to also take into account time spent in uninterrupted periods of these PA types. Our results also showed that, compared to non-shift workers, hospital shift workers spent less time climbing stairs at work. Climbing stairs is a potentially health-enhancing vigorous type of PA (46). Together with the findings regarding sitting and standing, this indicates that more research 
is needed to assess whether shift workers engage in occupational PA that is less beneficial for health than it is for non-shift workers.

\section{Strengths and limitations}

A key strength of the present study lies in its measurement of PA using accelerometry. The resulting objective PA measures are more valid and reliable than selfreported PA measures $(23,24)$. Furthermore, occupational and leisure-time PA were separated, and different types of PA were taken into account. The high average accelerometer wear-time shows that most participants properly adhered to the protocol $(38,47)$. Another strength is that, due to the relatively large group of shift workers with objective PA data in this study, we were able to provide more insight into the current gap in the literature with respect to PA levels of shift workers during weeks with and without night shifts.

Of the approximately 18000 healthcare workers who were approached to participate, only $3 \%$ enrolled in Klokwerk+. Our population may therefore not be fully representative of the general population working in the healthcare sector. However, for the purpose of comparing PA levels of hospital shift and non-shift workers, the impact of this possibly limited generalizability of our results is considered minimal. Nonetheless, it is important to note that our results apply to hospital workers and should not be undoubtedly generalized to other occupational sectors. Another limitation of the current study is that shift and non-shift workers differed in sociodemographics and possibly also in work-related factors. Ideally, the only difference between the group of shift and non-shift workers is whether they perform shift work. However, shift work in the healthcare sector may be inherently linked to performing other tasks at work than non-shift workers, which makes it difficult to filter out the specific effects of shift work on PA. By adjusting the analyses for educational level and occupation, the impact of differences in work tasks was reduced. Nonetheless, no information on specific work tasks of shift and non-shift workers was available in the current study. To better understand occupational PA differences between shift and non-shift workers, gaining information on this matter is recommended for future studies.

\section{Concluding remarks}

According to our results, leisure-time PA levels of hospital shift and non-shift workers are similar. These findings together with those of previous studies (16-18, $21,39,40)$ indicate that it is unlikely that leisure-time PA plays an important role in the negative health effects of shift work. With respect to occupational PA, we found that hospital shift workers are less sedentary and more physically active at work than non-shift workers, indicating possible differences in work tasks. The differences in occupational PA between hospital shift and non-shift workers found in this study stress the importance of gaining insight into potential health effects for shift workers.

\section{Acknowledgements}

This study was funded by the Strategic Program project 24/7 Health of the Dutch National Institute for Public Health and the Environment (RIVM). The funding bodies had no role in the study design; collection, analysis, and interpretation of data; writing of the manuscript; or the decision to submit the manuscript for publication. The authors would like to thank Jorgen Skøtte and colleagues from the NRCWE for their help in collecting and processing the data. Furthermore, they thank Johan Werkhoven, Lindey de Jong, Michelle in 't Veld, Anni Yang, and Yvonne de Vries for their assistance during the data collection of Klokwerk+.

\section{Conflict of interest}

The authors declare no conflicts of interest.

\section{Protection of research participants}

Approval of the study was obtained from the institutional review board of the University Medical Center Utrecht, Utrecht, The Netherlands on March 15, 2016 (study protocol number 16-044/D, NL56022.041.16). Informed consent was obtained from all participants.

\section{References}

1. European Foundation for the Improvement of Living and Working Conditions (Eurofound). Sixth European Working Conditions Survey - Overview report. Luxembourg: Publications Office of the European Union; 2016.

2. Costa G. Shift work and health: current problems and preventive actions. Safety and health at work. 2010;1(2):112 23. https://doi.org/10.5491/SHAW.2010.1.2.112.

3. Lin X, Chen W, Wei F, Ying M, Wei W, Xie X. Night-shift work increases morbidity of breast cancer and all-cause mortality: a meta-analysis of 16 prospective cohort studies. Sleep Med. 2015;16(11):1381-7. https://doi.org/10.1016/j. sleep.2015.02.543.

4. Proper KI, Van de Langenberg D, Rodenburg W, Vermeulen RCH, Van der Beek AJ, Van Steeg H, et al. The relationship between shift work and metabolic risk factors: a systematic review of longitudinal studies. Am J 
Prev Med. 2016;50(5):e147-57. https://doi.org/10.1016/j. amepre.2015.11.013.

5. Vyas MV, Garg AX, Iansavichus AV, Costella J, Donner A, Laugsand LE, et al. Shift work and vascular events: systematic review and meta-analysis. BMJ (Clinical research ed). 2012;345:e4800. https://doi.org/10.1136/bmj.e4800.

6. Antunes LC, Levandovski R, Dantas G, Caumo W, Hidalgo MP. Obesity and shift work: chronobiological aspects. Nutr Res Rev. 2010;23(1):155-68. https://doi.org/10.1017/ S0954422410000016.

7. Fritschi L, Glass DC, Heyworth JS, Aronson K, Girschik J, Boyle T, et al. Hypotheses for mechanisms linking shiftwork and cancer. Med Hypotheses. 2011;77(3):430-6. https://doi. org/10.1016/j.mehy.2011.06.002.

8. Merkus SL, Holte KA, Huysmans MA, van Mechelen W, van der Beek AJ. Nonstandard working schedules and health: the systematic search for a comprehensive model. BMC Public Health. 2015;15:1084. https://doi.org/10.1186/s12889-0152407-9.

9. Puttonen S, Harma M, Hublin C. Shift work and cardiovascular disease - pathways from circadian stress to morbidity. Scand J Work Environ Health. 2010;36(2):96-108. https://doi. $\operatorname{org} / 10.5271 /$ sjweh.2894.

10. Ma CC, Burchfiel CM, Fekedulegn D, Andrew ME, Charles LE, Gu JK, et al. Association of shift work with physical activity among police officers: the Buffalo cardio-metabolic occupational police stress study. J Occup Environ Med. 2011;53(9):1030-6. https://doi.org/10.1097/ JOM.0b013e31822589f9.

11. Peplonska B, Burdelak W, Krysicka J, Bukowska A, Marcinkiewicz A, Sobala W, et al. Night shift work and modifiable lifestyle factors. Int J Occup Med Environ Health. 2014a;27(5):693-706. https://doi.org/10.2478/s13382-0140298-0.

12. Vandelanotte C, Short C, Rockloff M, Di Millia L, Ronan $\mathrm{K}$, Happell B, et al. How do different occupational factors influence total, occupational, and leisure-time physical activity? J Phys Act Health. 2015;12(2):200-7. https://doi. org/10.1123/jpah.2013-0098.

13. Atkinson G, Davenne D. Relationships between sleep, physical activity and human health. Physiol Behav. 2007;90(2-3):22935. https://doi.org/10.1016/j.physbeh.2006.09.015.

14. Chappel SE, Verswijveren S, Aisbett B, Considine J, Ridgers ND. Nurses' occupational physical activity levels: A systematic review. Int J Nurs Stud. 2017;73:52-62. https://doi. org/10.1016/j.ijnurstu.2017.05.006.

15. Bekkers MB, Koppes LL, Rodenburg W, van Steeg H, Proper KI. Relationship of night and shift work with weight change and lifestyle behaviors. J Occup Environ Med. 2015;57(4):e37-44. https://doi.org/10.1097/JOM.0000000000000426.

16. De Bacquer D, Van Risseghem M, Clays E, Kittel F, De Backer G, Braeckman L. Rotating shift work and the metabolic syndrome: a prospective study. Int J Epidemiol. 2009;38(3):848-54. https://doi.org/10.1093/ije/dyn360.

17. Hulsegge G, Gupta N, Holtermann A, Jorgensen MB, Proper
KI, van der Beek AJ. Shift workers have similar leisure-time physical activity levels as day workers but are more sedentary at work. Scand J Work Environ Health. 2017;43(2):127-35. https://doi.org/10.5271/sjweh.3614.

18. Kivimaki M, Kuisma P, Virtanen M, Elovainio M. Does shift work lead to poorer health habits? A comparison between women who had always done shift work with those who had never done shift work. Work Stress. 2001;15:3-13. https://doi. org/10.1080/02678370118685.

19. Loprinzi PD. The effects of shift work on free-living physical activity and sedentary behavior. Prev Med. 2015;76:43-7. https://doi.org/10.1016/j.ypmed.2015.03.025.

20. Tada Y, Kawano Y, Maeda I, Yoshizaki T, Sunami A, Yokoyama Y, et al. Association of body mass index with lifestyle and rotating shift work in Japanese female nurses. Obesity (Silver Spring). 2014;22(12):2489-93. https://doi. org/10.1002/oby.20908.

21. van Amelsvoort LG, Schouten EG, Kok FJ. Impact of one year of shift work on cardiovascular disease risk factors. J Occup Environ Med. 2004;46(7):699-706. https://doi. org/10.1097/01.jom.0000131794.83723.45.

22. Nabe-Nielsen K, Quist HG, Garde AH, Aust B. Shiftwork and changes in health behaviors. J Occup Environ Med. 2011;53(12):1413-7. https://doi.org/10.1097/ JOM.0b013e31823401f0.

23. Prince SA, Adamo KB, Hamel ME, Hardt J, Connor Gorber S, Tremblay M. A comparison of direct versus self-report measures for assessing physical activity in adults: a systematic review. Int J Behav Nutr Phys Act. 2008;5:56. https://doi. org/10.1186/1479-5868-5-56.

24. Troiano RP, Berrigan D, Dodd KW, Masse LC, Tilert T, McDowell M. Physical activity in the United States measured by accelerometer. Med Sci Sports Exerc. 2008;40(1):181-8. https://doi.org/10.1249/mss.0b013e31815a51b3.

25. Andersen LB, Schnohr P, Schroll M, Hein HO. All-cause mortality associated with physical activity during leisure time, work, sports, and cycling to work. Arch Intern Med. 2000;160(11):1621-8. https://doi.org/10.1001/ archinte.160.11.1621.

26. Hamer M, Chida Y. Walking and primary prevention: a meta-analysis of prospective cohort studies. $\mathrm{Br} \mathrm{J}$ Sports Med. 2008;42(4):238-43. https://doi.org/10.1136/ bjsm.2007.039974.

27. Patel AV, Bernstein L, Deka A, Feigelson HS, Campbell PT, Gapstur SM, et al. Leisure time spent sitting in relation to total mortality in a prospective cohort of US adults. Am J Epidemiol. 2010;172(4):419-29. https://doi.org/10.1093/aje/ kwq155.

28. Chau JY, van der Ploeg HP, Merom D, Chey T, Bauman AE. Cross-sectional associations between occupational and leisuretime sitting, physical activity and obesity in working adults. Prev Med. 2012;54(3-4):195-200. https://doi.org/10.1016/j. ypmed.2011.12.020.

29. Holtermann A, Hansen JV, Burr H, Sogaard K, Sjogaard G. The health paradox of occupational and leisure-time physical 
activity. Br J Sports Med. 2012a;46(4):291-5. https://doi. org/10.1136/bjsm.2010.079582.

30. Holtermann A, Krause N, van der Beek AJ, Straker L. The physical activity paradox: six reasons why occupational physical activity (OPA) does not confer the cardiovascular health benefits that leisure time physical activity does. Br J Sports Med. [Epub ahead of print] 10 August 2017. https:// doi.org/10.1136/bjsports-2017-097965.

31. Li J, Loerbroks A, Angerer P. Physical activity and risk of cardiovascular disease: what does the new epidemiological evidence show? Curr Opin Cardiol. 2013;28(5):575-83. https://doi.org/10.1097/HCO.0b013e328364289c.

32. Loef B, van Baarle D, van der Beek AJ, van Kerkhof LW, van de Langenberg D, Proper KI. Klokwerk+ study protocol: An observational study to the effects of night-shift work on body weight and infection susceptibility and the mechanisms underlying these health effects. BMC Public Health. 2016;16:692. https://doi.org/10.1186/s12889-016-3317-1.

33. Stevens RG, Hansen J, Costa G, Haus E, Kauppinen T, Aronson KJ, et al. Considerations of circadian impact for defining 'shift work' in cancer studies: IARC Working Group Report. Occup Environ Med. 2011;68(2):154-62. https://doi. org/10.1136/oem.2009.053512.

34. Gupta N, Christiansen CS, Hallman DM, Korshoj M, Carneiro IG, Holtermann A. Is objectively measured sitting time associated with low back pain? A cross-sectional investigation in the NOMAD study. PLoS One. 2015;10(3):e0121159. https://doi.org/10.1371/journal.pone.0121159.

35. Skotte J, Korshoj M, Kristiansen J, Hanisch C, Holtermann A. Detection of physical activity types using triaxial accelerometers. J Phys Act Health. 2014;11(1):76-84. https:// doi.org/10.1123/jpah.2011-0347.

36. Hallman DM, Mathiassen SE, Gupta N, Korshoj M, Holtermann A. Differences between work and leisure in temporal patterns of objectively measured physical activity among blue-collar workers. BMC Public Health. 2015;15:976. https://doi.org/10.1186/s12889-015-2339-4.

37. Healy GN, Matthews CE, Dunstan DW, Winkler EA, Owen N. Sedentary time and cardio-metabolic biomarkers in US adults: NHANES 2003-06. Eur Heart J. 2011;32(5):590-7. https:// doi.org/10.1093/eurheartj/ehq451.

38. Mâsse LC, Fuemmeler BF, Anderson CB, Matthews CE, Trost SG, Catellier DJ, et al. Accelerometer data reduction: a comparison of four reduction algorithms on select outcome variables. Med Sci Sports Exerc. 2005;37(11 Suppl):S544-54. https://doi.org/10.1249/01.mss.0000185674.09066.8a.
39. Esquirol Y, Bongard V, Mabile L, Jonnier B, Soulat JM, Perret B. Shift work and metabolic syndrome: respective impacts of job strain, physical activity, and dietary rhythms. Chronobiol Int. 2009;26(3):544-59. https://doi. org/10.1080/07420520902821176.

40. Peplonska B, Bukowska A, Sobala W. Rotating night shift work and physical activity of nurses and midwives in the cross-sectional study in Lodz, Poland. Chronobiol Int. 2014b;31(10):1152-9. https://doi.org/10.3109/07420528.20 14.957296 .

41. Loyen A, van der Ploeg HP, Bauman A, Brug J, Lakerveld J. European Sitting Championship: Prevalence and Correlates of Self-Reported Sitting Time in the 28 European Union Member States. PLoS One. 2016;11(3):e0149320. https://doi. org/10.1371/journal.pone.0149320.

42. Jackson EJ, Moreton A. Safety during night shifts: a crosssectional survey of junior doctors' preparation and practice. BMJ Open. 2013;3(9):e003567. https://doi.org/10.1136/ bmjopen-2013-003567.

43. Coenen P, Gilson N, Healy GN, Dunstan DW, Straker LM A qualitative review of existing national and international occupational safety and health policies relating to occupational sedentary behaviour. Appl Ergon. 2017;60:320-33. https://doi. org/10.1016/j.apergo.2016.12.010.

44. Waters TR, Dick RB. Evidence of health risks associated with prolonged standing at work and intervention effectiveness. Rehabil Nurs. 2015;40(3):14865. https://doi.org/10.1002/ rnj.166.

45. Chen J, Daraiseh NM, Davis KG, Pan W. Sources of workrelated acute fatigue in United States hospital nurses. Nurs Health Sci. 2014;16(1):19-25. https://doi.org/10.1111/ nhs. 12104

46. Meyer P, Kayser B, Mach F. Stair use for cardiovascular disease prevention. Eur J Cardiovasc Prev Rehabil. 2009;16 Suppl 2:S17-8. https://doi.org/10.1097/01. hjr.0000359230.73270.2e.

47. Ward DS, Evenson KR, Vaughn A, Rodgers AB, Troiano RP. Accelerometer use in physical activity: best practices and research recommendations. Med Sci Sports Exerc. 2005;37(11 Suppl):S582-8. https://doi.org/10.1249/01. mss.0000185292.71933.91.

Received for publication: 12 October 2017 